\title{
ÉPOCA DE FLORESCIMENTO E HORAS DE FRIO PARA PESSEGUEIROS E NECTARINEIRAS ${ }^{1}$
}

\author{
MARIO JOSÉ PEDRO JÚNIOR ${ }^{3}$, WILSON BARBOSA ${ }^{3}$, GLAUCO DE SOUZA ROLIM ${ }^{3}$, JAIRO LOPES DE CASTRO
}

RESUMO - Avaliou-se a época de florescimento de 41 acessos de pessegueiros e nectarineiras existentes no Banco Ativo de Germoplasma (BAG) de Frutas de Caroço, em Capão Bonito-SP. As datas de abertura espontânea de 70\% das flores (sem indução por produtos químicos) foram observadas e relacionadas com o número de horas de frio (NHF) abaixo de 7,2 e $13^{\circ} \mathrm{C}$. O NHF foi estimado, utilizandose de equações de regressão múltipla em função das temperaturas máximas e mínimas diárias. Os acessos do referido BAG foram separados por meio de análise de "cluster", resultando na identificação de quatro grupos distintos para pessegueiros, em relação a épocas de florescimento (até 10-07; 11-07 a 20-07; 21-07 a 31-07 e após $1^{\circ}-08$ ), e três para nectarineiras (até 10-07; 11-07 a 20-07 e após 20-07). Dentre esses grupos, o mais precoce apresentou florescimento antes de 10 de julho, com exigência inferior a 40 e 500 NHF abaixo de 7,2 e $13^{\circ} \mathrm{C}$, respectivamente, para pêssego (IAC 2485-6, IAC 680-13 e Régis) e nectarina (IAC N 785-9). O grupo mais tardio para pêssegos (Eldorado, Diamante, Arlequim, Bolão e Marli) apresentou florescimento após $1^{\circ}$ de agosto, necessitando de mais de 70 e 650 NHF abaixo de 7,2 e $13^{\circ} \mathrm{C}$, respectivamente. As principais cultivares de pêssego da persicultura paulista (Aurora-1, Douradão e Dourado-1) floresceram entre 11 e 20 de julho com NHF entre 41 a 50 abaixo de $7,2^{\circ} \mathrm{C}$ e entre 501 a 560 abaixo de $13^{\circ} \mathrm{C}$.

Termos para indexação: Prunus persica, endodormência, persicultura.

\section{BLOSSON DATE AND CHILLING HOURS REQUIREMENTS UNDER $7.2^{\circ} \mathrm{C}$ AND $13^{\circ} \mathrm{C}$ FOR PEACHES AND NECTARINES AT CAPÃO BONITO, SP, BRAZIL}

\begin{abstract}
Blossom dates for 41 peaches and nectarines accesses from the Active Gene Bank (BAG) of stone fruits were evaluated at Capão Bonito (SP), Brazil. Observations of flowering date ( $70 \%$ of opened flowers) were taken and compared to the chilling hour's requirement (NHF) considering 7.2 and $13^{\circ} \mathrm{C}$. The NHF was estimated using multiple regression equations based on maximum and minimum temperature. The accesses from the BAG were separated by cluster analysis into four groups for peaches and three for nectarines by cluster analysis. The following peaches accesses: IAC 2485-6, IAC 680-13 and Régis and for nectarine: IAC N 785- 9 showed flowering date before July $10^{\text {th }}$ with NHF less than 40 and 500, below 7.2 and $13^{\circ} \mathrm{C}$, respectively. The peach cultivars Eldorado, Diamante, Arlequim, Bolão, and Marli showed blossom dates after August $1^{\text {st }}$, requiring more than 70 and $650 \mathrm{NHF}$ bellow 7.2 and $13^{\circ} \mathrm{C}$, respectively. The main peach cultivars for São Paulo State like: Aurora-1, Douradão and Dourado-1, flowered from July 11 to 20 with NHF from 41 to 50 bellow $7.2^{\circ} \mathrm{C}$ and from 501 to 560 bellow $13^{\circ} \mathrm{C}$.
\end{abstract}

Index terms: Prunus persica, endodormancy, stone fruit.

\section{INTRODUÇÃO}

As frutíferas de caroço vêm se constituindo em importante opção para a diversificação dos produtos agrícolas no Estado de São Paulo. Seu cultivo econômico, em regiões consideradas nãotradicionais, deve-se ao emprego de material melhorado, principalmente pelo Instituto Agronômico (IAC), disponibilizando cultivares aclimatadas às condições de inverno ameno. A adaptabilidade do pessegueiro às diferentes condições ecofisiológicas mundiais deve-se à seleção genética de cultivares melhoradas, tanto de baixa como de alta exigência de frio (NHF, número de horas de frio). Hoje, encontram-se cultivos de pêssego e nectarina nas mais variadas condições de clima e solo, desde regiões com inverno bem rigoroso (600-1.200 NHF abaixo de $\left.7,2^{\circ} \mathrm{C}\right)$, até em outras praticamente desprovidas de frio hibernal (menos de $20 \mathrm{HF}$ abaixo de $7,2^{\circ} \mathrm{C}$ ) (Barbosa et al., 1989).

O início da safra paulista ocorre em época antecipada, em relação aos Estados do Sul do Brasil. Essa precocidade de maturação é decorrente do clima hibernal mais quente, da utilização de cultivares próprias e técnicas subsidiárias especiais de cultivo. As cultivares desenvolvidas para São Paulo, com variados ciclos de maturação dos frutos, permitem atender ao mercado desde setembro até fevereiro, disponibilizando aos consumidores uma série de diferentes tipos de pêssegos e de nectarinas (Barbosa et al., 1997). Excetuando a videira, que representa cerca de $50 \%$ de toda a área ocupada pela fruticultura em São Paulo, o pessegueiro é hoje a principal frutífera de clima temperado cultivada no Estado, com cerca de 2 milhões de plantas, incluindo-se a nectarineira, que equivale a $15 \%$ da persicultura

${ }^{1}$ (Trabalho 200-06). Recebido: 29-11-2006.Aceito para publicação:23-10-2007. Pesquisa integrante do projeto IAC: "Caracterização da biodiversidade e das espécies, cultivares e seleções de frutíferas de clima temperado no Estado de São Paulo"

${ }_{3}^{3}$ Pesquisadores Científicos, Instituto Agronômico (IAC/APTA/SAA), Caixa Postal 28, 13001-970 Campinas-SP. E-mail: mpedro@iac.sp.gov.br; wbarbosa@iac.sp.gov.br. Bolsistas de produtividade em pesquisa do CNPq.

${ }^{4}$ Pesquisador Científico, Instituto Agronômico (IAC/APTA/SAA), Caixa Postal 28, 13001-970 Campinas-SP. rolim@iac.sp.gov.br.

Rev. Bras. Frutic., Jaboticabal - SP, v. 29, n. 3, p. 425-430, Dezembro 2007 
paulista em número de plantas (Barbosa et al., 2003).

Mesmo com os significativos avanços científicos e tecnológicos, ocorridos nas últimas duas décadas, verifica-se carência de cultivares completamente adaptadas às condições climáticas paulistas de pouco frio hibernal. Assim, a plena expansão da cultura das frutas de caroço tem sido limitada por certos fatores primordiais: os insuficientes testes regionais para indicação de cultivares adaptadas às diferentes regiões ecológicas; a falta de caracterização fenológica dos variados genótipos existentes, e o desconhecimento da exigência de horas de frio para o normal desenvolvimento vegetativo e floral.

Para a quebra da endodormência das gemas floríferas e vegetativas, é necessário que as frutíferas de climas temperado sejam submetidas a um período de baixas temperaturas, usualmente conhecidas como horas de frio (Herter et al., 1998). É conhecida a necessidade que certas espécies vegetais têm de satisfazer determinado número de horas com baixas temperaturas, durante o período de hibernação, para que as fases fenológicas subseqüentes se completem sem provocar variações na produtividade. Alguns estudos foram realizados para a determinação das exigências em frio, hibernação em pessegueiro e/ou nectarineira. Iuchi (1990) relatou que cultivares de baixa exigência em frio hibernal, provenientes do programa de melhoramento do Estado de São Paulo, adaptaram-se bem no Espírito Santo, com valores de 150 a 200 horas de frio. Nienow \& Licodiedoff (1996), avaliando a variabilidade fenológica de cultivares de pessegueiro e nectarineira no planalto médio do Rio Grande do Sul, relataram ser a duração média do período de florescimento de 18 dias, porém variações ocorreram em função do número de horas de frio entre 250 e 500 horas. Nienow \& Floss (2002) também avaliaram a florescimento de 12 cultivares de pessegueiro e nectarineira em Passo Fundo (RS), indicando ter havido interferência dos fatores climáticos na data de florescimento e brotação das cultivares, que ocorreu entre os meses de julho e agosto. Citadin et al. (2002), em Pelotas (RS), determinaram a necessidade de frio de seis cultivares de pessegueiro como sendo entre 200 e 418 horas abaixo de $12{ }^{\circ} \mathrm{C}$.

Cultivares de pêssego e nectarina vêm sendo cultivadas em regiões com invernos relativamente quentes no Estado de São Paulo, com disponibilidade de horas de frio entre 40 e 80 horas abaixo de $7,2^{\circ} \mathrm{C}$ (Pedro Jr. et al., 1979). Pereira et al. (2002), ao analisarem as respostas de algumas cultivares de pêssego e nectarina, verificaram que, dentre elas, a cultivar Aurora-1 apresentou as maiores produções de frutos nas condições climáticas de Jaboticabal-SP.

A caracterização das necessidades térmicas, das diferentes cultivares e seleções de pêssego e nectarina, permitirá fornecer subsídios importantes às culturas, visando à melhor adaptação aos diferentes ambientes climáticos das áreas de cultivo.

Considerando-se a influência do material genético e das condições climáticas na época de florescimento, desenvolveu-se este trabalho, objetivando: (a) determinação de NHF abaixo de $7,2^{\circ} \mathrm{C}(\mathrm{NHF}<7,2)$ e $13^{\circ} \mathrm{C}(\mathrm{NHF}<13)$ a partir de temperaturas mínimas e máximas para a região de Capão Bonito-SP, e (b) classificação de 34 variedades de pêssegos e sete de nectarinas em grupos semelhantes com relação às respostas de NHF e data de florescimento espontânea.

\section{MATERIAL E MÉTODOS}

Foram avaliadas datas de florecimento das diferentes cultivares e seleções de pessegueiros $(\mathrm{P})$ e nectarineiras $(\mathrm{N})$ : a) Cultivares antigas: Talismã $(\mathrm{P})$, Tutu $(\mathrm{P})$, Ouromel $(\mathrm{P})$, Cristal $(\mathrm{P})$, Arlequim (P), Biuti (P), Bolão (P), Canário (P), Taichi (P) e Real (P); b) Cultivares novas: Tropical-1 $(\mathrm{P})$, Douradão $(\mathrm{P})$, Aurora-1 $(\mathrm{P})$, Dourado-1 (P), Jóia-1 (P), Régis (P), Centenário (P), Doçura-2 (P), Josefina $(\mathrm{N})$ e Centenária $(\mathrm{N})$; c) Seleções: IAC 6882-84 (P); IAC 2982-24 (P); IAC 680-177 (P); IAC 680-13 (P); IAC 2485-6 (P); IAC 1085-6 (P); IAC 2982-24 (P); IAC 1085-7 (P); IAC N 785-9 (N); IAC N 2680-91 (N), e IAC N 5483-19 (N); e d) Cultivares introduzidas: Maravilha (P), Rubro-sol (N), Tropic Beauty (P), Sunraycer (N), Flordaprince (P), Premier (P), Eldorado (P), Marli (P), Diamante (P) e Riograndense (P).

O ensaio foi desenvolvido em pessegueiros e nectarineiras com espaçamento de $3 \times 2$ metros, em plantas enxertadas em pêssego Okinawa, com idade de 5 anos no início do experimento, conduzidas com três a cinco pernadas, instalado em área experimental da APTA Regional do Sudoeste Paulista, em Capão Bonito-SP (latitude: $24^{\circ} 00^{\prime} \mathrm{S}$, longitude: $48^{\circ} 22^{\prime} \mathrm{W}$, altitude: $702 \mathrm{~m}$ ). $\mathrm{O}$ clima segundo Köppen é $\mathrm{Cfa}$, subtropical com verão quente $\mathrm{e}$ estação seca moderada no inverno com temperatura média anual de $19,1^{\circ} \mathrm{C}$ (Setzer, 1966).

As datas de florescimento espontâneo (sem indução por produtos químicos) foram obtidas entre junho e agosto de 1998 a 2001 com delineamento inteiramente casualizado, observando-se as datas de abertura de $70 \%$ das flores em três ramos localizados no terço médio de cada copa. Foram analisadas duas plantas por material do BAG-Frutas de caroço, totalizando 6 repetições.

Para a avaliação de $\mathrm{NHF}<7,2$ e NHF $<13$, foram utilizados dados da variação horária da temperatura do ar, disponíveis em registros (termogramas) na estação meteorológica situada a 300 $m$ do experimento. Para a complementação dos dados, foi utilizado método de estimativa em função da relação de amplitudes térmicas (RA) , como sugerido por Pola et al. (1994) e adaptado para a região de Capão Bonito, no período de abril a agosto:

$$
\mathrm{NHF}=\mathrm{a}+\mathrm{b} * \mathrm{RA}+\mathrm{c} * \mathrm{RA}^{2}
$$

em que NHF é o número de horas de frio abaixo de 7,2 ou $13^{\circ} \mathrm{C}$; $\mathrm{RA}=24 *((\mathrm{~K}-\mathrm{Tmín}) /($ Tmáx - Tmín $))$

a; b; c são coeficientes da equação de regressão e $\mathrm{K}$ tem valor de 7,2 ou $13^{\circ} \mathrm{C}$, Tmín e Tmáx são as temperaturas mínimas e máximas diárias $\left({ }^{\circ} \mathrm{C}\right)$. Os valores estimados de NHF negativos foram transformados em zero, e os superiores a 24 foram igualados a 24 horas.

As cultivares e seleções utilizadas no experimento são de ciclo precoce, mediano e tardio, de baixa e de média exigência em frio, que foram agrupadas de acordo com suas características fenológicas, por meio da análise de "cluster", utilizando "simple linkage (nearest neighbor)" para a determinação das distâncias euclidianas (Cooley \& Lhones, 1971), combinando a época de florescimento (quebra de endodormência) com $\mathrm{NHF}<7,2$ e com 
$\mathrm{NHF}<13$. Após esta análise, tanto para os pessegueiros como para as nectarineiras, foi possível a separação dos grupos de cultivares com as mesmas características de exigências climáticas. A variabilidade dos dados de $N H F<13$ e data de quebra de endodormência (dia juliano) de cada grupo foram avaliados por gráficos tipo "box-plot", onde foram apresentados a média, o desvio- padrão e os valores extremos. Essas análises forneceram subsídios para a montagem de um quadro final, onde os acessos foram separados em diferentes grupos, de acordo com suas exigências climáticas.

\section{RESULTADOS E DISCUSSÃO}

Os resultados obtidos foram relativos ao número de horas de frio, enfocando a equação de estimativa e disponibilidade para Capão Bonito-SP e florescimento espontâneo dos 41 acessos de nectarineiras e pessegueiros para posterior uso destas informações para a determinação dos grupos similares.

\section{Estimativa do número de horas de frio}

Para completar os dados de NHF $<7,2$ e $\mathrm{NHF}<13$ para o período considerado, não constantes dos termogramas, foram adaptadas para a região de Capão Bonito as seguintes equações de regressão:

$\mathrm{NHF}<7,2=0,374+1,767 \mathrm{RA}-0,0558 \mathrm{RA}^{2}(\mathrm{r}=0,79 * *)$

$$
\mathrm{NHF}<13=1,803+1,122 \mathrm{RA}-0,0077 \mathrm{RA}^{2}(\mathrm{r}=0,84 * *)
$$

As equações obtidas para a estimativa do número de horas de frio, considerando o período de abril a agosto de 1998 a 2001, mostraram-se significativas, ao nível de $1 \%$, pelo teste $\mathrm{F}$. Os valores obtidos dos coeficientes de RA e RA ${ }^{2}$ foram semelhantes aos obtidos por Pola et al. (1994) em estimativas de NHF $<7,2$ e NHF $<13$, para diferentes localidades de Santa Catarina.

\section{Disponibilidade de horas de frio}

Na Tabela 1, são apresentados os valores de temperatura mínima média mensal e o total mensal do $\mathrm{NHF}<7,2$ e NHF $<13$ de abril a agosto de 1998 a 2001. Os menores valores de temperatura mínima ocorreram durante junho $\left(9,9 ; 9,8^{\circ} \mathrm{C}\right)$ para 1998 e 1999 ; em julho $\left(7,8^{\circ} \mathrm{e} 9,7^{\circ} \mathrm{C}\right)$ para 2000 e 2001 e em agosto $\left(9,3^{\circ} \mathrm{C}\right)$ para 1999. Nesses meses, o NHF $<13$ atingiu valores de 240 e 340 horas. Foi observado que, em 1999 e 2000, o acúmulo foi elevado devido à ocorrência (em junho de 1999 e julho de 2000) de dias com temperaturas mínimas absolutas de $-2,2^{\circ} \mathrm{C}$ e $0,2^{\circ} \mathrm{C}$, elevando o $\mathrm{NHF}<13$ para cerca de 340 horas.

\section{Análise de Agrupamento ou "Cluster"}

Os valores médios das datas de florescimento espontânea, com $70 \%$ das flores abertas, das 41 cultivares de pêssego e nectarina, no período de 1998 a 2001, e o NHF $<13$ acumulado entre abril e agosto, permitiram o agrupamento por meio de análise de "cluster" das diferentes cultivares e seleções de pessegueiro e nectarineira (Figura 1). Foi verificado que a análise de agrupamento, utilizando-se de $\mathrm{NHF}<7,2^{\circ} \mathrm{C}$, não permitiu a distinção dos grupos.
Esta análise permitiu o agrupamento dos acessos em cinco grandes grupos em relação à $\mathrm{NHF}<13$ e a data de florescimento, concomitantemente. A variabilidade dos valores de $\mathrm{NHF}<13$ e a data de florescimento de cada grupo são apresentadas na Figura 2, que evidencia a relativa sobreposição dos grupos P2 e P3.

Dessa forma, avaliando-se esses resultados, foi feita uma tabela final (Tabela 2), que agrega os acessos do BAG-frutas de caroço em quatro grupos distintos (P1, P2, P3 e P4) para pessegueiros e três grupos para nectarineiras (N1, N2 e N3). Os acessos IAC 2485-6, IAC 680-13 e Régis, foram os de menor exigência em horas de frio (Grupo P1), pois a quebra natural da endodormência ocorreu, em média, antes de 10-07, com valores de $\mathrm{NHF}<13$ abaixo de 500 horas.

A maior parte das seleções e cultivares foi agrupada para época de florescimento espontânea entre 11-07 e 20-07, quando o acúmulo observado de $\mathrm{NHF}<13$ se estabeleceu entre 501 e 560 horas (Grupo P2). São elas: IAC 680-177; IAC 2982-24; IAC 688284; IAC 1085-7; IAC 1085-6; Centenário; Jóia-1; Aurora-1; Maravilha; Tropic Beauty; Tropical-1; Tutu; Doçura-2; Cristal; Flordaprince; Canário; Talismã; Ouromel; Dourado-1 e Douradão.

Os principais pêssegos da persicultura paulista, como Aurora-1, Douradão e Dourado-1, floresceram entre a segunda e a terceira semana de julho, em média, com NHF de 41 a 50 horas abaixo de $7,2^{\circ} \mathrm{C}$ e de 501 a 560 abaixo de $13^{\circ} \mathrm{C}$. Em relação às cultivares Premier, Biuti, Taichi, Real e Rio-Grandense observouse que a quebra natural da endodormência, caracterizada pela abertura espontânea do botão floral, ocorreu entre 21-07 e 31-07 com valores de $\mathrm{NHF}<13$ entre 561 e 650 horas (Grupo P3).

As cultivares com florescimento mais tardio e mais exigentes em horas de frio foram: Eldorado, Diamante, Marli, Arlequim e Bolão. Nestas, o florescimento ocorreu após $1^{\circ}$ de agosto, com $\mathrm{NHF}<13$ superior a 650 horas (Grupo P4). Ressaltese que as duas últimas cultivares de pêssegos, além da florada, apresentam também maturação bem tardia dos frutos, com ciclo médio de 190 dias (Barbosa et al., 1990). Já as cultivares Eldorado (Citadin et al., 2002) e Marli, desenvolvidas na Embrapa - Clima Temperado, em Pelotas-RS, são relatadas como exigentes em frio e de florescimento tardio, porém possuem ciclo de maturação dos frutos de cerca de 120 dias.

Levando-se em consideração as cultivares e seleções de nectarineira, observou-se que a IAC N 785-9 foi a menos exigente em horas de frio $(\mathrm{NHF}<13<500)$, com florescimento natural ocorrendo antes de 10-07 (Grupo N1). As cultivares e seleções: Josefina, Centenária, IAC N 2680-91 e IAC N 5483-19 apresentaram florescimento entre 11-07 e 20-07, com valores de NHF $<13$ entre 501 e 560 horas (Grupo N2). As cultivares com florescimento mais tardio e mais exigentes em frio foram: Rubro-sol e Sunraycer, com abertura do botão floral após 20-07, que exigiram $\mathrm{NHF}<13$ superior a 560 horas (Grupo N3).

A separação das cultivares e seleções de pêssego, em quatro grupos de exigência climática e três grupos de nectarineiras, permitirá melhor planejamento das práticas culturais, como o tratamento de inverno, a poda e a aplicação de produtos para quebra de endodormência das gemas. 
TABELA1- Temperatura mínima média mensal e número de horas de frio abaixo de $7,2(\mathrm{NHF}<7,2)$ e $13^{\circ} \mathrm{C}(\mathrm{NHF}<13)$, no período de abril a agosto de 1998 a 2001, em Capão Bonito (SP).

\begin{tabular}{|c|c|c|c|c|c|}
\hline \multirow{2}{*}{ Ano } & \multicolumn{5}{|l|}{ Mês } \\
\hline & \multirow[t]{2}{*}{ Abril } & Maio & Junho & \multicolumn{2}{|c|}{ Julho Agosto } \\
\hline & & \multicolumn{4}{|c|}{ Temperatura mínima } \\
\hline 1998 & 15,9 & 11,9 & 9,9 & 11,1 & 13,3 \\
\hline 1999 & 14,7 & 11,0 & 9,8 & 11,4 & 9,3 \\
\hline 2000 & 14,3 & 11,5 & 10,9 & 7,8 & 10,1 \\
\hline \multirow[t]{2}{*}{2001} & 16,9 & 12,3 & 11,8 & 9,7 & 12,5 \\
\hline & & \multicolumn{4}{|c|}{$\mathrm{NHF}<7,2$ (horas) } \\
\hline 1998 & o & 5 & 9 & 18 & 0 \\
\hline 1999 & 16 & 29 & 5 & 0 & 31 \\
\hline 2000 & o & 23 & 24 & 103 & 17 \\
\hline \multirow[t]{2}{*}{2001} & o & 7 & 34 & 20 & 0 \\
\hline & & \multicolumn{4}{|c|}{$\mathrm{NHF}<13$ (horas) } \\
\hline 1998 & 36 & 126 & 270 & 177 & 82 \\
\hline 1999 & 70 & 178 & 340 & 171 & 248 \\
\hline 2000 & 44 & 170 & 162 & 343 & 220 \\
\hline 2001 & 4 & 153 & 164 & 240 & 100 \\
\hline
\end{tabular}

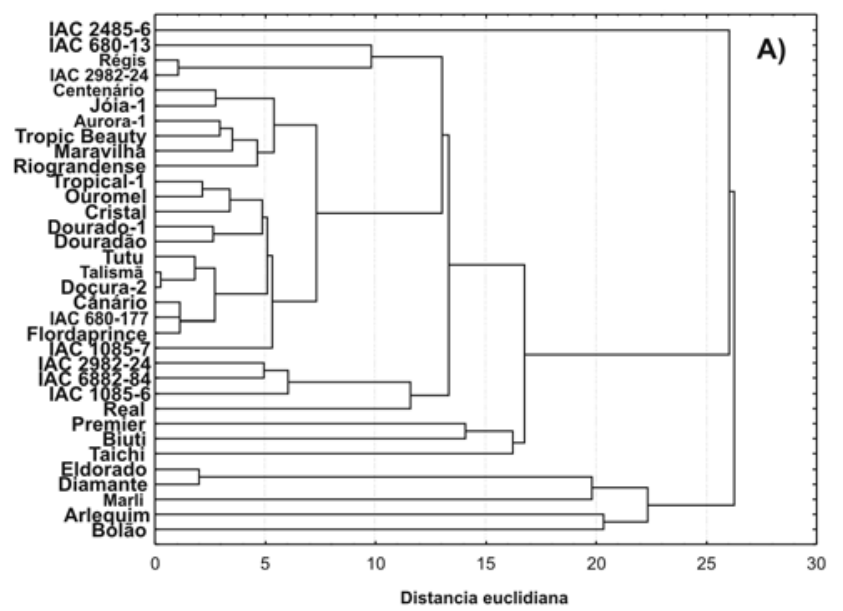

TABELA 2- Grupos de cultivares de mesma necessidade de número de horas de frio (NHF) abaixo de $7,2^{\circ} \mathrm{C}$ $(\mathrm{NHF}<7,2)$ e de $13^{\circ} \mathrm{C}(\mathrm{NHF}<13)$, acumulados a partir de $1^{\circ}$ de abril, e data de florescimento $(70 \%$ de flores abertas), para as cultivares de pêssego e nectarina, em Capão Bonito-SP, no período de 1998 a 2001 .

\begin{tabular}{|c|c|c|c|c|}
\hline \multirow[t]{2}{*}{ Grupo } & Cultivar / & $\mathrm{NHF}<7,2$ & \multirow{2}{*}{$\begin{array}{c}\mathrm{NHF}<13 \\
\text { (horas) }\end{array}$} & \multirow{2}{*}{$\begin{array}{c}\text { Data de } \\
\text { Florescimento }\end{array}$} \\
\hline & Seleção de pêssego & (horas) & & \\
\hline P1 & $\begin{array}{l}\text { IAC 2485-6; IAC 680-13; } \\
\text { Régis }\end{array}$ & $<40$ & $<500$ & $<10-07$ \\
\hline $\mathrm{P} 2$ & $\begin{array}{l}\text { Centenário; Jóia-1; Aurora-1; } \\
\text { Maravilha; Tropic Beauty; } \\
\text { Tropical-1; Tutu; Canário; Talismã; } \\
\text { Ouromel; Dourado-1; IAC 680-177; } \\
\text { Doçura-2; Cristal; Flordaprince; } \\
\text {; IAC 6882-84; Douradão; } \\
\text { IAC 1085-7; IAC 1085-6, } \\
\text { IAC 2982-24 }\end{array}$ & 41 a 50 & 501 a 560 & $11-07$ a $20-07$ \\
\hline P3 & $\begin{array}{l}\text { Premier; Biuti; Taichi; Real; } \\
\text { Riograndense }\end{array}$ & 51 a 70 & 561 a 650 & $21-07$ a $31-07$ \\
\hline \multirow[t]{2}{*}{ P4 } & $\begin{array}{l}\text { Eldorado; Diamante; Arlequim; } \\
\text { Bolão; Marli }\end{array}$ & $>70$ & $>650$ & $>01^{\circ}-08$ \\
\hline & Cultivar/Seleção de nectarina & & & \\
\hline N1 & IAC N 785-9 & $<40$ & $<500$ & $<10-07$ \\
\hline $\mathrm{N} 2$ & $\begin{array}{l}\text { Josefina; Centenária; IAC N 2680-91 } \\
\text { IAC N 5483-19 }\end{array}$ & 41 a 50 & 501 a 560 & $11-07$ a $20-07$ \\
\hline N3 & Rubro-sol; Sunraycer & $>50$ & $>560$ & $>20-07$ \\
\hline
\end{tabular}

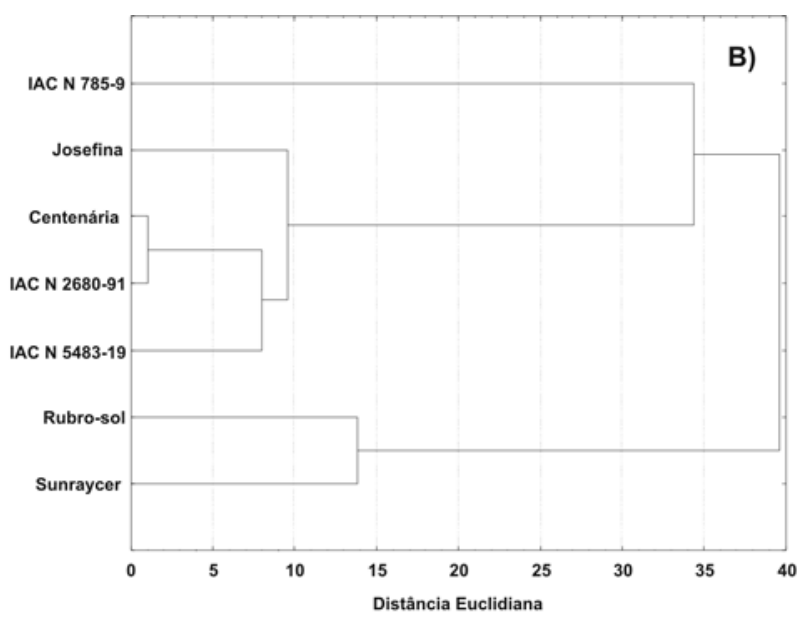

FIGURA 1- Análise de "Cluster" usando "simple linkage" para a determinação das distâncias euclidianas utilizando médias de número de horas de frio abaixo de $13^{\circ} \mathrm{C}$ e época de florescimento (dia Juliano) para diversas cultivares de pêssegos (A) e de nectarinas (B), em Capão Bonito-SP, no período de 1998 a 2001. 

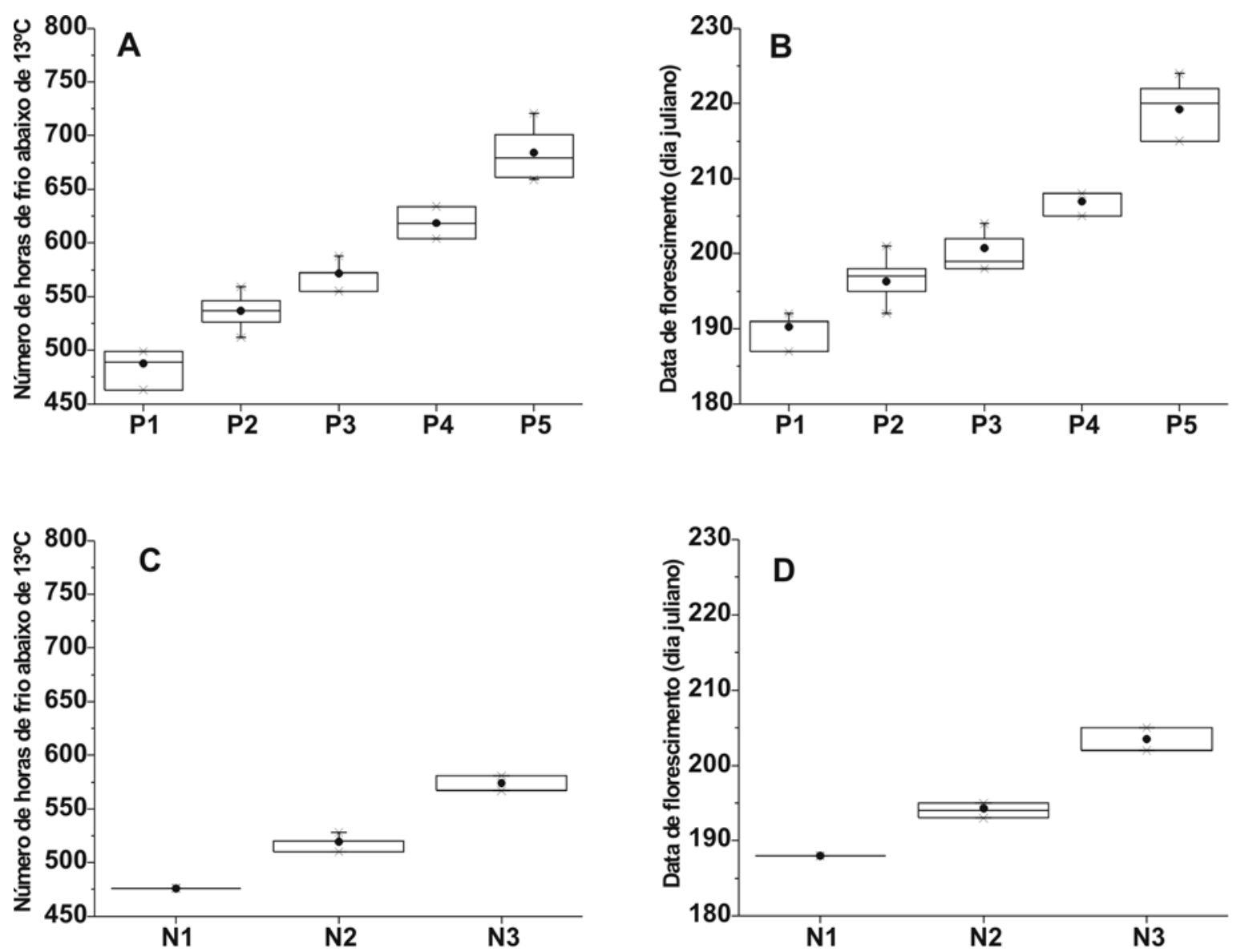

FIGURA 2- Dispersão dos dados de número de horas de frio abaixo de $13^{\circ} \mathrm{C}$ e data de florescimento para os diversos grupos determinados pela análise de "cluster", para cultivares de pêssegos (gráficos: A e B; grupos: P1, P2, P3, P4 e P5) e nectarinas (gráficos: C e D; grupos: N1, N2 e N3). Legenda: • Média, ¡\% Desvio-padrão, - Dispersão dos dados 1 a 99\%, $\times$ valores mínimos e máximos, em Capão Bonito-SP, no período de 1998 a 2001.

\section{CONCLUSÕES}

Para as condições de Capão Bonito-SP, conclui-se que:

1- É possível a estimativa do número de horas de frio abaixo de $7,2^{\circ} \mathrm{C}$ e $13{ }^{\circ} \mathrm{C}$ por meio de equações de regressão múltipla em função de temperaturas máxima e mínima.

2 - $\mathrm{O}$ uso do número de horas de frio abaixo de $13^{\circ} \mathrm{C}$ e a data de florescimento, são viáveis para a separação das cultivares em diferentes grupos de similaridade.

3- Os principais pêssegos da persicultura paulista, como Aurora-1, Douradão e Dourado-1, florescem entre 11 e 20 de julho, com número de horas de frio de 41 a 50 horas abaixo de $7,2^{\circ} \mathrm{C}$ e de 501 a 560 horas abaixo de $13^{\circ} \mathrm{C}$.

\section{REFERÊNCIAS}

BARBOSA, W.; CAMPO-DALL'ORTO, F.A.; OJIMA, M.; SAMPAIO, V.R.; BANDEL, G. Ecofisiologia do desenvolvimento vegetativo e reprodutivo do pessegueiro em região subtropical. Campinas: Instituto Agronômico, 1989. (Documentos IAC, 17)

BARBOSA, W.; OJIMA, M.; CAMPO-DALL'ORTO, F.A.; RIGITANO, O.; MARTINS, F.P.; SANTOS, R.R.; CASTRO, J.L. Melhoramento do pessegueiro para regiões de clima subtropicaltemperado: realizações do Instituto Agronômico no período de 1950 a 1990. Campinas: Instituto Agronômico, 1997. 22p. (Documentos IAC, 52)

BARBOSA, W.; OJIMA, M.; CAMPO-DALL'ORTO, F.A.; MARTINS, F.P. Época e ciclo de maturação de pêssegos e nectarinas no Estado de São Paulo. Bragantia, Campinas, v.49, n.2, p. 221-226, 1990 . 
BARBOSA, W.; POMMER, C.V.; RIBEIRO, M.D.; VEIGA, R.F.A.; COSTA, A.A. Distribuição geográfica e diversidade varietal de frutíferas e nozes de clima temperado no Estado de São Paulo. Revista Brasileira de Fruticultura, Jaboticabal, v.25, n.2, p.341$344,2003$.

CITADIN, I.; RASEIRA, M.C.B; HERTER, F.G.; SILVEIRAC.A.P. Avaliação da necessidade de frio em pessegueiro. Revista Brasileira de Fruticultura, Jaboticabal, v.24, n.3, p.703-706, 2002. COOLEY, W.W.; LOHNES, P.R. Multivariate analysis. New York: Ed. John Wiley \& Sons, 1971.

HERTER, F.G.; SACHS, S.; FLORES, S.A. Condições edafoclimáticas para instalação do pomar. In: MEDEIROS, C.A.B.; RASEIRA, M do C.B. (Eds). A cultura do pessegueiro. Brasília: EMBRAPA, 1998. p.20-28.

IUCHI, T. Comportamento preliminar de cultivares de pêssego e nectarina na região serrana do Espírito Santo. Revista Brasileira de Fruticultura, Cruz de Almas, v.12, n.3, p.25-29. 1990

NIENOW, A.A.; FLOSS, L.G. Florescimento de pessegueiros e nectarineiras no planalto médio do Rio Grande do Sul, influenciada pelas condições meteorológicas. Ciência Rural, Santa Maria, v.32, n.6, p.931-936, 2002.
NIENOW,A.A; LICODIEDOFF, M.C. Comportamento fenológico e produtivo de cultivares de pessegueiro e nectarineira no planalto médio do Rio Grande do Sul. Revista Brasileira de Fruticultura, Cruz das Almas, v.18. n.2, p. 201-208. 1996.

PEDRO JÚNIOR, M.J.; ORTOLANI, A.A; RIGITANO, O.; ALFONSI, R.R.; PINTO, H.S.; BRUNINI, O. Estimativa de horas de frio abaixo de $7 \mathrm{e} \mathrm{de} 13^{\circ} \mathrm{C}$ para regionalização da fruticultura de clima temperado no Estado de São Paulo. Bragantia, Campinas, v.38, p.123-130, 1979.

PEREIRA, F.M.; NACHTIGAL, J.C.; ROBERTO, S.R. Tecnologia para a cultura do pessegueiro em regióes tropicais e subtropicais. Jaboticabal: Funep, 2002. 62p.

POLA, A.C.; BLEICHER, J; BERNARDI, J. Avaliação de modelo de unidades e horas de frio para a previsão do início de brotação em macieira, cv. Gala. Revista Brasileira de Fruticultura, Cruz de Almas, v.16, n.1, p.105-118. 1994.

SETZER, J. Atlas climático e ecológico do Estado de São Paulo. São Paulo: Ed. Comissão Interestadual da Bacia Paraná-Uruguai, 1996. 61p.. 